\title{
Oui à l'initiative «Contre la violence par les armes» - prévention du suicide avant tout
}

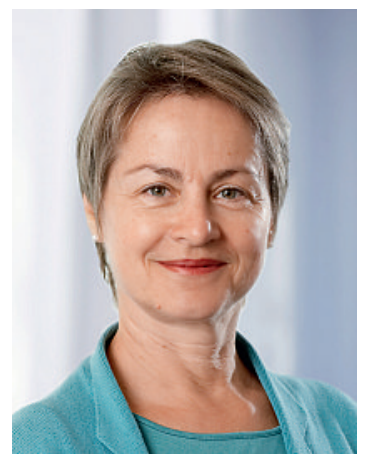

«Service de garde. Peu avant minuit, un appel de la police: venez immédiatement... un suicide... c'est dramatique, un jeune homme s'est tiré une balle dans la bouche remplie d'eau avec l'arme de service de son père (une carabine).» C'est ainsi que Benedikt Horn débute sa lettre de lecteur par laquelle il remercie les délégués de la FMH de soutenir l'initiative «Pour la protection face à la violence des armes» [1]. Chez plus d'un lecteur certainement, ces lignes auront rappelé des souvenirs similaires de scènes effroyables; on déplore plus de 300 suicides avec des armes à feu par an - pratiquement un chaque jour. A cet égard d'ailleurs, la Suisse détient un triste record en comparaison internationale et - fait particulièrement

\section{Ce sont principalement des hommes jeunes qui se suicident au moyen de leur arme de service.}

affligeant - ce sont principalement les jeunes hommes qui mettent fin à leurs jours au moyen de leur arme de service [2].

Une loi sur les armes plus restrictive est-elle réellement la solution? Ou la prédisposition au suicide est-elle inhérente aux personnes concernées? La prévention du suicide relèvet-elle uniquement du médecin traitant et de la personne concernée? Faut-il se résoudre à penser que celui ou celle qui veut se suicider trouvera toujours un moyen de passer à l'acte? Nous médecins savons à quel point il est essentiel de reconnaître la propension au suicide de nos patients et d'agir en conséquence. Or cela n'est pas toujours simple. Le jeune homme dont Benedikt Horn a dû attester le décès, avait consulté son médecin traitant la veille. Un bon médecin, selon le Dr Horn. Et là de nouveau, beaucoup d'entre nous connaissent ce que ressentent les proches après un suicide, ou justement aussi les soignants qui n'ont pas pu aider.

Il faut l'implication de l'ensemble de la société pour arriver à comprendre la suicidalité et développer différentes stratégies d'action. Il est incontestable que la prévention du suicide relève du domaine de la santé publique. Dans son rapport, le Conseil fédéral écrit que «les mesures de santé publique tentent d'influencer les conditions de vie et l'environnement de la population générale, de certains groupes et d'individus. Elles visent, d'une part, la promotion de la santé (...), et, d'autre part, à sensibiliser la population aux maladies psychiques, à créer et à promouvoir des structures à bas seuil, à rendre plus difficile l'accès aux moyens et méthodes permettant de mettre fin à ses jours, ainsi qu'à établir un code de conduite sur le traitement du suicide par les médias.» [3]. Dans son message relatif à l'initiative populaire, le Conseil fédéral confirme: «Ce qui est certain, en revanche, c'est qu'une limitation de la disponibilité des armes à feu contribue à la diminution des taux de suicide. Dans les pays qui, au cours des deux dernières décennies, ont réussi à restreindre l'accès aux armes à feu (comme par ex. le Canada, l'Australie, l'Ecosse, l'Angleterre et le Pays de Galles), non seulement le nombre de suicides par arme à feu a diminué,

\section{La prévention du suicide peut être simple: une arme qui n'est pas immédiatement disponible, c'est un instant de répit.}

mais aussi le taux de suicide en général. Il est en effet prouvé que les instruments ou méthodes de suicide ne sont pas interchangeables» [4]. En lisant ces lignes, on ne comprend guère pourquoi le Conseil fédéral recommande malgré tout de rejeter l'initiative - encore un mystère de la politique fédérale...

Rien ne justifie qu'une arme à feu - qui permet de mettre facilement fin à ses jours - soit si aisément disponible. Je pense au cas auxquels j'ai été confrontée dans mon activité de psychiatre: à ce père de famille qui lors d'un repas de famille un peu arrosé, s'est rendu à l'étage supérieur de sa maison - apparemment pour y chercher quelque chose - et dont la dernière chose que sa famille a entendu de lui fut le coup de feu qu'il s'est tiré. Ou cet employé qui venait de prendre sa retraite et qui s'est tiré une balle dans la tête alors que sa femme s'était absentée un moment pour aller chercher du lait pour le café du matin. Toutes ces histoires ont été racontées par des proches qui, bien des années plus tard, restent marqués par les conséquences d'un tel acte.

Cet élément du puzzle de la prévention du suicide est si simple à obtenir: une arme qui n'est pas disponible à la maison, c'est un instant de répit. Cela ne permet évidemment pas de prévenir chaque suicide, mais à coup sûr certains d'entre eux. Chaque sursis donne une chance à la volonté de vivre - ne faut-il pas saisir absolument cette occasion? Un oui le 13 février 2011 à l'initiative «Pour la protection contre la violence des armes» nous aidera à sauver des vies.

Dr Christine Romann, membre du Comité central de la FMH Responsable du domaine Promotion de la santé et prévention

\section{Références}

1 Horn B. Kurzbericht von «Tatort» an den FMH-Präsidenten. Bull Méd Suisses. 2007;88(31/32): 1297.

2 Habenstein A, Bartsch C, Reisch T. Pilotstudie zu Nationalfondsprojekt: Suicide in Switzerland: A detailed survey of the years 2000 to $2010 ; 2010$.

3 Le suicide et la prévention du suicide en Suisse, rapport répondant au postulat Widmer (02.3251); avril 2005.

4 Message relatif à l'initiative «Pour la protection face à la violence des armes» du 16 décembre 2009. 